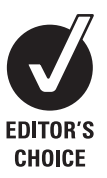

Correspondence to: Dr I Philibert, Accreditation Council for Graduate Medical Education, 515 North State Street, Suite 2000, Chicago, IL 60654, USA; iphilibert@acgme.org

Accepted 7 May 2009

\title{
Use of strategies from high-reliability organisations to the patient hand-off by resident physicians: practical implications
}

\author{
| Philibert
}

\begin{abstract}
Background: Limits on resident hours increase the frequency of patient hand-offs and may contribute to information transfer problems that contribute to adverse outcomes. This study analysed attributes that affect handoff accuracy, including use of data summaries and end-ofshift transfer strategies from high-reliability organisations. Method: Mixed-method study combining qualitative interviews and surveys of residents in internal medicine, surgery, paediatrics and ob-gynaecology.
\end{abstract}

Findings: Strategies in resident hand-offs mirrored the intent of end-off-shift transfers in high-reliability organisations, but approaches differed, reflecting the fluid nature of residents' work and focusing on multiple patients with differing needs. Clinical skills were relevant to hand-off quality for both participants. Cross-coverage, more common duty hour limits, had a negative effect on hand-off accuracy. It significantly increased the likelihood of unplanned changes in care and errors attributed to the hand-off. For surgery residents, asynchronous hand-offs without true interactions increased. Data summaries contributed to efficiency, but were associated with greater incidence of surprises and errors, even when they did not replace verbal hand-offs. Third parties, particularly nursing, functioned as redundant systems that prevented or trapped many hand-off errors.

Conclusions: Hand-offs depended on residents' clinical skills, suggesting a need for education and supervision of junior residents' transfers. Research is needed to explore how to conduct effective hand-offs under shortened duty periods. This should assess how transfer strategies and data summaries could enhance efficiency and effectiveness, and how they could substitute when a verbal interactive hand-off is not feasible.

High-quality care takes into consideration patients' condition, current status and prior treatment, and applying them to decision-making and patient management. Limits on resident hours and growth in shift- and team-based approaches have increased the frequency of patient hand-offs, when responsibility for patients is transferred. Research has identified the hand-off as a vulnerable period in the care process during which information may be lost, distorted or misinterpreted.

This study had three aims: (1) identify aspects of hand-offs that contribute to vulnerability from a safety perspective; (2) assess how increased turnover of care under limited duty hours has affected hand-offs, including the contribution to errors and unplanned changes in care; and (3) analyse whether use of data summaries and end-ofshift transfer strategies from high-reliability organisations $^{1}$ improves accuracy and could compensate for problems attributed to more frequent and time-constrained hand-offs. Related to these aims, the article presents practical recommendations for improving teaching and practice of resident hand-offs.

\section{LITERATURE REVIEW}

Medicine continues to be characterised by greater reliance on human cognition and memory for information processing and communication than other industries at risk for high-stakes failures. Errors or omissions in information transfers among care givers increase the risk for adverse consequences, when erroneous information becomes "fact" for the person or team receiving and using it. $^{23}$ Research on closed malpractice claims in teaching settings implicated teamwork breakdowns in $70 \%$ of cases, with hand-off errors the second most prevalent problem after lack of supervision. ${ }^{4}$ Communication failures also were found to contribute to $60 \%$ of healthcare sentinel events. ${ }^{5}$ Residents believe hand-offs are not adequately addressed in education and practice, noting processes are haphazard and there is no system of organised interaction. ${ }^{67}$

Limits on resident hours implemented in 2003 have increased the frequency of hand-offs, and may have reduced the time available for transferring information. They also have contributed to increased use of scheduling models such as nightfloat and cross-coverage, under which residents may be less familiar with patients under their care. Care by a cross-covering physician has been associated with longer hospitalisations and more laboratory tests, with the difference nearly reaching statistical significance, ${ }^{8}$ and has also been associated with a significant increase in the odds for errors. ${ }^{9}$ Studies of the effect of the duty hour limits, despite large sample sizes, found little change in patient mortality during the 2 years following implementation, particularly for surgical patients. ${ }^{10-12}$ Recent research found a small increase in medication errors in paediatrics residents under duty hour limits, attributed to problems with hand-offs. ${ }^{13}$ This has prompted concerns that frequent and time-constrained hand-offs may frustrate the aims of the duty hour limits. A recent Institute of Medicine (IOM) report about resident hours and condition to optimise patient safety recommended that all residents should receive education in patient hand-offs, and made research to improve hand-offs a high priority. ${ }^{14}$ 
High-reliability organisations function in high-risk domains in a "nearly error-free fashion." 15 Patterson et al studied four settings with critical need for accurate end-of-shift information transfers. Their findings showed similar strategies used across settings to enhance the effectiveness and efficiency of end-ofshift information transfers, which the authors felt could be used to improve patient hand-offs. ${ }^{1}$ Research on data summaries to support hand-offs to reduce reliance on memory has reported enhanced efficiency and high acceptance by residents. ${ }^{16}$ There may be trade-offs, including summaries creating "information overload" and failure to recognise critical information, especially in novice physicians. ${ }^{17}$ Problems also may arise when summaries replace interactive communication, which can pinpoint critical data items and offer context. ${ }^{18}$

\section{STUDY DESIGN}

This study used a multimethod approach, combining qualitative interviews and surveys of residents in internal medicine, surgery, obstetrics-gynaecology and paediatrics, who participated in hand-offs in the role of outgoing (end of duty period) and incoming (start of duty period) physician. Programmes selected for both the interview study and the more quantitative survey were of median or above size for their specialty.

\section{Qualitative study}

Residents and faculty completed 12-question structured interviews about the hand-off between December 2004 and June 2006. Selected follow-up interviews were conducted in early 2007 to validate selected findings from the quantitative survey. Resident participants were randomly chosen from listings of residents available on public websites, and from lists provided by programme leadership. If a resident declined participation, sampling moved to the next individual on the list. Resident selection focused on "typical" cases to enhance generalizability, while selection of faculty used purposeful sampling to select "information rich" participants with knowledge of resident education and the hand-off. ${ }^{19}$ Participants gave permission and were assured confidentiality.

\section{Quantitative study}

Residents on inpatient rotations at University of Iowa and the Henry Ford Health System completed surveys for individual hand-offs that collected attributes of good and problematic hand-offs, with items adapted for the role of outgoing and incoming resident. The surveys also collected information on the use and utility of strategies from high-reliability organisations and formal hand-off data summaries. Surveys were completed over an 11-month period from April 2006 to March 2007. Institutions were solicited by the investigator.

The surveys used a seven-point Likert scale, with "strongly agree" and "strongly disagree" anchors, and free text for selected questions. The items for hand-off errors were adapted from Petersen et al's study of adverse events in patient care transitions, which defined them as "surprises" and "unexpected events." 20 For surveys where respondents reported an error or surprise, they were asked to complete additional questions about circumstances and contributing factors. A pretest of the form with eight residents used a thought-listing approach. ${ }^{21}$ Based on their feedback, several revisions were made to the instrument.

Residents received a bonus ( $\$ 10)$ for each completed survey. Participants were consented, and Institutional Review Board (IRB) approval was obtained at both institutions.

\section{DATA COLLECTION AND ANALYSIS}

\section{Qualitative study}

Interview data were coded and analysed by the researcher, using OSR Nvivo qualitative analysis software and an inductive approach. $^{22}$ Interviews were conducted until "theoretical saturation" 23 was reached, with added participants unable to offer new information. This occurred after interviewing 30 residents and 20 faculty physicians collectively representing 31 different residency programmes. Follow-up interviews encompassed eight faculty physicians with knowledge of the hand-off.

\section{Quantitative study}

Outgoing physicians completed surveys immediately after the hand-off, and incoming physicians at the conclusion of their duty period. Eighty-six residents $(74 \%$ of the residents consented) completed hand-off surveys. The majority were first- and second-year residents, consistent with the greater emphasis on inpatient care during the early years of residency. Across all specialties, participants completed 844 surveys (418 surveys from outgoing, and 426 surveys from incoming physicians). Nineteen additional surveys were not usable due to insufficient items completed. Descriptive statistics are shown in table 1. A partial explanation for the low participation by Obstetrics-Gynaecology residents could be clinical demands, and the fact that this was the only programme for which the researcher was not able to identify a senior resident to function as a liaison and champion for the study.

\section{FINDINGS}

\section{Hand-off process and the effect of shortened shifts}

\section{Qualitative study}

Verbal interactive hand-offs predominated in internal medicine, obstetrics-gynaecology and paediatrics, and interviewees estimated they made up one-half of hand-offs in surgery. During face-to-face hand-offs, residents relied on multiple modes of communication-written, verbal and non-verbal cues such as gestures and emphasis. Interviewees expressed a preference for verbal, interactive hand-offs. When these did not occur, reasons included time constraints and dispersion of patients across the institution, with residents having to travel significant distances to meet face to face. The majority of hand-offs without a faceto-face exchange were conducted over the telephone, yet 15$20 \%$ of the hand-offs in surgery and a small proportion of those in other specialties were asynchronous, consisting solely of the outgoing resident leaving a electronic or paper summary or handwritten notes. Participants reported that the number of asynchronous hand-offs was increasing.

Residents and faculty reported that hand-off quality depended on residents' clinical and diagnostic skills. Understanding clinical conditions and likely contingencies and events allowed the outgoing physician to focus on relevant information, and was important to the incoming's ability to comprehend the importance of this information in the context of the given patient. Mechanisms for conveying information favoured the outgoing making handwritten notes for verbal sharing with the incoming. Residents also used informal decision algorithms to deal with the wealth of information in the hand-off.

The interviews found that confidence in hand-off participants' abilities was important, with residents reporting they made judgements about the value of information based on prior clinical interactions. Trust and prior positive interactions between participants also allowed an expanded conversation that clarified patient status, contingencies and care plans. 
Table 1 Descriptive statistics

\begin{tabular}{llllll}
\hline & $\begin{array}{l}\text { Residents } \\
\text { consented }\end{array}$ & $\begin{array}{l}\text { Residents } \\
\text { participating }\end{array}$ & $\begin{array}{l}\text { Percentage } \\
\text { participating }\end{array}$ & $\begin{array}{l}\text { Outgoing } \\
\text { surveys } \\
\text { completed }\end{array}$ & $\begin{array}{l}\text { Incoming surveys } \\
\text { completed }\end{array}$ \\
\hline Internal Medicine-University of lowa & 26 & 23 & 88 & 112 & 114 \\
Internal Medicine-Henry Ford Hospital & 32 & 29 & 91 & 98 & 103 \\
Obstetrics-Gynaecology & 15 & 2 & 13 & 8 & 6 \\
Paediatrics & 26 & 17 & 65 & 91 & 88 \\
Surgery & 17 & 15 & 88 & 109 & 115 \\
Total & 116 & 86 & 74 & 418 & 426 \\
\hline
\end{tabular}

In settings that used formal data summaries, residents reported that the number of data items in the forms may detract from a focus on the information critical for managing patients. In contrast, handwritten notes focused on patients' current status, likelihood of complications or events and "to do" lists for the upcoming duty period.

Hand-offs more vulnerable for errors lacked true two-way exchange of information. In addition to asynchronous handoffs, this included hand-offs between residents not comfortable with each other, hand-offs that adhered very closely to a predesigned hand-off data form, and hand-offs on the first day of a rotation or when residents returned from vacation or other absence (potentially a combination of time constraints and participants' disconnection from the clinical context). Two other studies also identified hand-offs after longer absences and by staff new in a setting as more prone to errors. ${ }^{24} 25$

Errors and communication problems in hand-offs included erroneous information for the given patient and omissions of planned tasks. Activities at highest risk for being "dropped" were those outstanding or unfinished at the end of the outgoing's shift. Residents reported that this rarely caused harm to patients, but it likely delayed needed care and may have extended some hospitalisations. Residents also implicated handoffs with data summaries as potentially vulnerable, because their use resulted in a "go down the list and report all information" paradigm, which reportedly detracted from the focus on the most relevant items.

Residents reported that not knowing who was responsible for patients was a frequent complaint of nurses and other personnel. Problems with coordination were more pronounced when face-to-face hand-offs did not occur (such as when a note and the pager were left for the incoming and an emergency prevented timely retrieval). This predated, but was made worse by, shorter shifts instituted in response the duty hour limits. Other research also found instances when the transfer of professional responsibility for patients occurred before the transfer of information about them. ${ }^{26}$

\section{Quantitative study}

Hand-offs lasted on average of just over $12 \mathrm{~min}$, with a very small number of hand-offs lasting significantly longer than $20 \mathrm{~min}$. The distribution of the number of patients and minutes per patient (table 2) shows significant skewness and a leptokurtic distribution for all specialties with the exception of paediatrics. A ceiling effect for total time for the hand-off is further confirmed by an inverse relationship $(r=-0.382)$ between the number of patients handed off and minutes per patient. Reasons include time constraints, more efficient handoffs with a large patient number due to a fixed time to establish rapport, and hand-offs under cross-coverage, which had the largest census, potentially occurring under a model of a reduced mandate for care and more limited information-sharing. ${ }^{27}$
Surprises (unexpected changes in care) occurred in 14\% (59 of 426) and errors/incidents in 9\% (39 of 426) of the hand-offs for which surveys were completed by the incoming physician. Table 3 shows that cross-coverage increased the odds of unplanned changes and errors attributed to the hand-off, while night float did not appear to present an added risk. Comments showed that when an event entailed sharing incorrect information, residents considered it an "error," while omissions and the rare significant changes in treatment due to an initially incorrect diagnosis were considered a "surprise." Diagnostic and care activities left unfinished at the end of the outgoing's shift was a factor in approximately $20 \%$ of errors and was the leading cause for events residents defined as surprises. Like the interview study, the survey found that errors and surprises rarely appeared to affect patients in significant ways. One important reason was the presence of "redundant" systems. This included other residents, faculty, but particularly nurses, who filled in missing information and/or caught errors and omissions attributed to the hand-off.

\section{Use of strategies from high-reliability organisations}

Analysis of the use of strategies from high-reliability organisations in the interviews and survey showed that some strategies were commonly used (table 4). This is similar to the finding of research on hand-offs from the emergency department, although the strategies used differed somewhat between the two settings. ${ }^{27}$ Overall, the attributes of resident hand-offs in the study met the intent of the high-reliability strategies, but the approaches differed to accommodate the mobile, fluid nature of patient hand-offs and the need to convey information on multiple patients with different needs for care. Two findings differed from earlier research on these strategies. ${ }^{1}{ }^{28}$ Read-back was not used. For selected important information items, participants reported use of two-way feedback to ensure receipt and understanding. Updating information in a consistent order was reported only in settings that used data summaries.

The interviews revealed that residents viewed four strategies from high reliability organisations in table 4 as goals for the hand-off to ensure continuity over successive duty periods and multiple residents: (1) conveying the outgoing's recommendations for plans and contingencies; (2) providing the incoming with up-to-date information; (3) ensuring an unambiguous transfer of responsibility; and (4) transparency to others about who is responsible for patients.

Use of data summaries was associated with increased efficiency with hand-offs averaging 1.15 min per patient (SD 0.91), compared with 1.7 min per patient (SD 1.23) for those without summaries. However, use of summaries was associated with increased odds ratios for errors $(7.682,95 \%$ CI 2.491 to 23.631, $p=0.000)$ and surprises $(7.161,95 \%$ CI 1.871 to 27.308 , $\mathrm{p}=0.001)$. Surgery residents reported few errors and did not use data summaries. A second analysis excluding them produced an 
Table 2 Distribution of patients and minutes per patient across three specialties

\begin{tabular}{|c|c|c|c|c|c|c|c|}
\hline & Mean & $\begin{array}{l}\text { Standard } \\
\text { deviation }\end{array}$ & t Value & Skewness & Kurtosis & Minimum & Maximum \\
\hline \multicolumn{8}{|l|}{ Internal medicine } \\
\hline No of patients & 11.84 & 7.38 & 23.35 & 0.80 & -0.13 & 1 & 33 \\
\hline $\begin{array}{l}\text { Minutes per } \\
\text { patient }\end{array}$ & 1.26 & 0.98 & 18.81 & 1.57 & 2.78 & 0.07 & 5.00 \\
\hline \multicolumn{8}{|l|}{ Paediatrics } \\
\hline No of patients & 12.27 & 5.31 & 15.51 & 1.45 & 2.61 & 5 & 31 \\
\hline $\begin{array}{l}\text { Minutes per } \\
\text { patient }\end{array}$ & 1.24 & 0.43 & 19.25 & -0.12 & -0.14 & 0.24 & 2.27 \\
\hline \multicolumn{8}{|l|}{ Surgery } \\
\hline No of patients & 6.67 & 3.75 & 19.06 & 2.55 & 11.27 & 1 & 27 \\
\hline $\begin{array}{l}\text { Minutes per } \\
\text { patient }\end{array}$ & 1.50 & 1.09 & 13.96 & 2.03 & 7.25 & 0.11 & 6.92 \\
\hline
\end{tabular}

odds ratio of 2.535 for errors, with the $95 \%$ confidence interval including one and the finding not reaching statistical significance, and a similar finding for surprises.

Use of informal notes in surgery residents' hand-offs blurred the distinction between hand-offs with and without data summaries, and there may be alternative explanations for the lower rate of errors in surgery residents' hand-offs. They include a potentially narrower range of diagnoses, contingencies and to do lists; greater supervision of junior residents by senior colleagues and faculty; and greater involvement of other healthcare personnel in the pre- and postoperative management of patients. It is also possible that surgery residents had rates of errors comparable with residents in the other specialties, but that reporting was constrained by shame or fear of repercussions or concerns about true anonymity of study participants.

\section{DISCUSSION AND PRACTICAL IMPLICATIONS}

Patient hand-offs are both resilient, given the constraints imposed, and vulnerable, due to their complexity and the fact that participants are learners. Selected results are important to efforts to teach and improve the patient hand-off. This includes the reliance of hand-offs on residents' clinical skills, which underpin the skills for communicating the information. Another is that hand-offs meet the goals of end-of-shift transfers in highreliability organisations, but that practices differ to accommodate the mobile, fluid nature of residents' work.

Five attributes of certain hand-offs contributed to problems, and present opportunities for practical interventions to improve teaching and practice:

- 1. Hand-offs truncated or omitted due to work demands or time constraints resulting from duty hour limits, with documentation replacing all or some of the interactive exchange.

- 2. Diagnostic and care activities unfinished at the end of the outgoing's shift and carried through a shift-change, which put them a higher risk of being "dropped."

- 3. Hand-offs participants perceived as challenging because residents may not know or trust each other, with lack of confidence in the outgoing physician's judgement a critical factor.

- 4. Hand-offs under cross-coverage, due to larger patient loads, lower familiarity with patients and an expectation of less information needing to be shared.

Table 3 Odds of surprises and incident/errors under different shift patterns

\begin{tabular}{|c|c|c|c|c|}
\hline Surprises (unplanned shifts in care) & Surprise & No surprise & $\begin{array}{l}\text { Odds ratio (95\% } \\
\text { confidence interval) }\end{array}$ & p Value \\
\hline Cross-cover only & 13 & 25 & 3.87 (1.87 to 8.01$)$ & 0.001 \\
\hline Day float & 2 & 46 & 0.25 (0.06 to 0.94$)$ & 0.004 \\
\hline In-house call & 25 & 197 & $0.77(0.45$ to 1.34$)$ & 0.401 \\
\hline Call and cross-cover & 7 & 14 & 3.39 (1.35 to 8.59$)$ & 0.008 \\
\hline Night float & 5 & 52 & $0.56(0.22$ to 1.47$)$ & 0.304 \\
\hline Night float and cross-cover & 4 & 14 & $1.83(0.61$ to 5.51$)$ & 0.293 \\
\hline Short call & 3 & 19 & $0.98(0.30$ to 3.22$)$ & 0.976 \\
\hline Any shift with cross-cover & 26 & 77 & 2.97 (1.68 to 5.24$)$ & 0.000 \\
\hline All & 59 & 367 & 1 & \\
\hline $\begin{array}{l}\text { Errors/incidents attributed } \\
\text { to the hand-off }\end{array}$ & Error/incident & $\begin{array}{l}\text { No error/ } \\
\text { incident }\end{array}$ & $\begin{array}{l}\text { Odds ratio ( } 95 \% \\
\text { confidence interval) }\end{array}$ & p Value \\
\hline Cross-cover only & 10 & 28 & 4.42 (1.99 to 9.87$)$ & 0.001 \\
\hline Day float & 1 & 47 & $0.19(0.03$ to 1.32$)$ & 0.105 \\
\hline In-house call & 18 & 204 & 0.35 (0.20 to 0.63$)$ & 0.000 \\
\hline Call and cross-cover & 6 & 15 & 6.20 (3.11 to 12.39 ) & 0.000 \\
\hline Night float & 2 & 55 & $0.33(0.09$ to 1.26$)$ & 0.140 \\
\hline Night float and cross-cover & 2 & 16 & $1.25(0.31$ to 5.11$)$ & 0.675 \\
\hline Short call & 0 & 22 & $0(-)$ & \\
\hline Any shift with cross-cover & 18 & 59 & $4.77(2.42$ to 9.41$)$ & 0.000 \\
\hline All & 39 & 387 & 1 & \\
\hline
\end{tabular}

Bold values indicate significance at the 0.005 level. 
Table 4 Use of strategies from high-reliability organisations

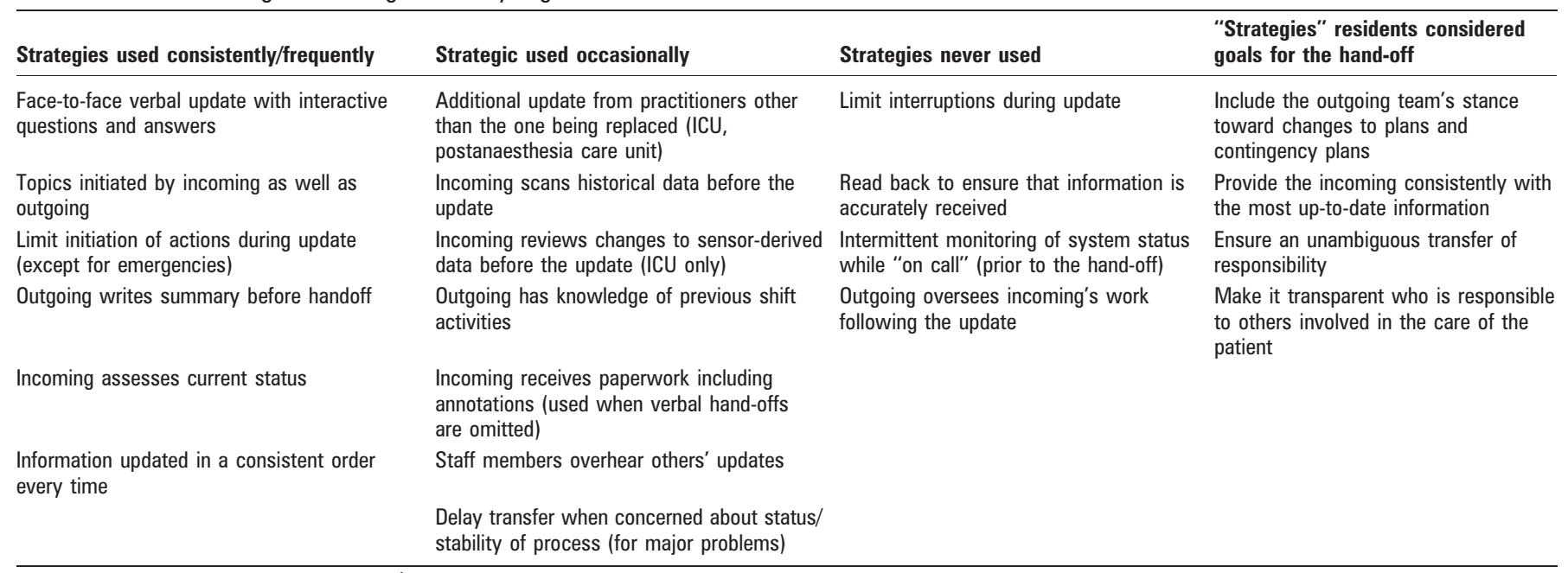

Strategies first reported by Patterson et al. ${ }^{1}$

- 5. Coordination problems and lack of a sense of who was responsible for patients, both among the residents and on the part of other professionals.

In the near term, three strategies will improve resident handoffs. First, teaching residents how to hand-off is essential and should focus equally on clinical decision-making and communicating the information clearly and efficiently. Second, the use of cross-coverage should be examined and where possible reduced or eliminated, due to the association with a sizeable increase in the odds for errors and surprises. Alternative staffing models may include larger teams with collective responsibility for patients across multiple units, or added faculty presence during the overnight period in a faculty-guided "night medicine" model. These alternatives carry time and opportunity costs for teaching institutions and their clinical staff, and it may be possible to mitigate the risks associated with cross-coverage through better education and enhanced focus on key elements of the hand-off in situations when residents will be less familiar with their patients. Third, increased involvement by senior residents, faculty and nursing could create redundant systems in an environment with high acuity, shortened resident shifts, and individuals learning the clinical and communication aspects of the hand-off.

\section{LIMITATIONS}

The study shares many of the methodological limitations of field studies, including limited sample size and lack of random assignment. To ensure programmes studied were representative, statistical and demographic information was compared, showing that programmes studied were larger than average but otherwise comparable with the national cohort in their specialty. Since hand-offs for which surveys were completed encompassed a small portion of total hand-offs for participants during the survey period, another potential limitation is sampling bias, the potential for selection of better than average hand-offs or those with likely errors or omissions. A related threat to validity may result from hindsight bias, a common problem in studies with after-the-fact attribution of causes for errors. ${ }^{29}$ In this study, knowledge of an error or surprise could have caused incoming residents to assess more negatively the outgoings' skills and their trust in them.

\section{CONCLUSIONS}

The findings support that improving the hand-off is important to enhancing the safety and continuity of inpatient care. Without effective hand-offs, current and potential future added limits on resident hours may result in an uncomfortable tradeoff-errors attributable to fatigue being replaced by errors due to inadequate transfer of information during the hand-off. Under team- and shift-based approaches to care, hand-offs are not limited to residents, and improving them is germane to safe and effective care. Thus, efforts ultimately will need to go beyond making learners, or any individuals, the repository and conveyors of this information, through creation of reliable systems to manage and move information critical to patient care. This should include finding more effective approaches for asynchronous hand-offs, including systems to support information transfer and continuity of care when residents cannot meet face to face.

Research also is needed to study the decision-making models and algorithms that underlie the hand-off, and how these could be better understood and taught to promote safe care during end-off-shift transfers. Related work includes efforts to enhance the salience of information in hand-offs through the use of three heuristics- "reduce, reveal and focus," with this approach based on naturalistic approaches to enhance decision-making. ${ }^{30} 31$ This research also may benefit the design of future hand-off summaries. Finally, work is needed to explore the best approaches to charge nurses, senior residents and faculty with assisting in the recovery of information lost or distorted in the hand-off. Research in all of these areas has a high potential of contributing to better approaches for hand-off teaching and practice.

Competing interests: IP is employed by the Accreditation Council for Graduate Medical Education (ACGME), which accredits residency programmes and sets standards for resident hours in the United States. The findings and conclusions are solely those of the author and do not represent the views of the ACGME.

Ethics approval: Ethics approval was provided by University of lowa Institutional Review Board (IRB) and Henry Ford Health System IRB.

Patient consent: Obtained.

\section{REFERENCES}

1. Patterson ES, Roth EM, Woods DD, et al. Handoff strategies in settings with high consequences for failure: lessons for health care operations. Int J Oual Health Care 2004; 16:125-32. 
2. Chassin MR, Becher EC. The wrong patient. Ann Intern Med 2002;136:826-33.

3. Reason JT, Carthey J, de Leval MR. Diagnosing "vulnerable system syndrome": an essential prerequisite to effective risk management. Qual Saf Health Care 2001;10(2 Suppl):ii21-5S.

4. Singh H, Thomas EJ, Petersen LA, et al. Medical errors involving trainees: a study of closed malpractice claims from 5 insurers. Arch Intern Med 2007;167:2030-6.

5. Joint Commission on the Accreditation of Healthcare Organizations. 2006 National Patient Safety Goals. http://www.jointcommission.org/PatientSafety/ NationalPatientSafetyGoals/06 npsg dsc.htm (accessed 8 Feb 2009).

6. Horwitz LI, Krumholz HM, Green ML, et al. Transfers of patient care between house staff on internal medicine wards: a national survey. Arch Intern Med 2006;166:1173-7.

7. Volpp GM, Grande D. Residents' suggestions for reducing errors in teaching hospitals. N Engl J Med 2003:348:851-5.

8. Lofgren RP, Gottlieb D, Williams RA, et al. Post-call transfer of resident responsibility: its effect on patient care. J Gen Intern Med 1990;5:501-5.

9. Petersen LA, Orav EJ, Teich JM. Using a computerized sign-out program to improve continuity of inpatient care and prevent adverse events. Jt Comm J Qual Improv 1998;624:77-87.

10. Volpp KG, Rosen AK, Rosenbaum PR, et al. Mortality among hospitalized Medicare beneficiaries in the first 2 years following ACGME resident duty hour reform. JAMA 2007;298:975-83.

11. Volpp KG, Rosen AK, Rosenbaum PR, et al. Mortality among patients in VA hospitals in the first 2 years following ACGME resident duty hour reform. JAMA 2007;298:984-92.

12. Shetty KD, Bhattacharya J. Changes in hospital mortality associated with residency work-hour regulations. Ann Intern Med 2007:147:73-80.

13. Landrigan $\mathbf{C P}$, Fahrenkopf AM, Lewin D, et al. Effects of the accreditation council for graduate medical education duty hour limits on sleep, work hours, and safety. Pediatrics 2008;122:250-8.

14. Institute of Medicine. Resident duty hours: enhancing sleep, supervision, and safety. Washington: National Academy of Sciences Press, 2008 December.

15. La Porte T, Consolini P. Theoretical and operational challenges of "high-reliability organizations:" air-traffic control and aircraft carriers. Int J Pub Admin 1998;21:847-52.

16. Van Eaton EG, Horvath KD, Lober WB, et al. Organizing the transfer of patient care information: the development of a computerized resident sign-out system. Surgery 2004;136:5-13.
17. Patel VL, Kushniruk AW, Yang S, et al. Impact of a computer-based patient record system on data collection, knowledge organization, and reasoning. J Am Med Inform Assoc 2000; 7:569-85

18. Brandwijk N, Nemeth C, O'Connor M, et al. Distributed cognition: ICU hand-offs conform to Grice's maxims. Poster, Presented at the Society for Critical Care Medicine, 2003, http://www.ctlab.org/documents/SCCMPoster1.27.03.pdf (accessed 23 Mar 2008).

19. Patton MO. Qualitative evaluation and research methods. 3rd edn. Newbury Park: Sage, 2000.

20. Petersen LA, Brennan TA, O'Neil AC, et al. Does housestaff discontinuity of care increase the risk for preventable adverse events? Ann Intern Med 1994;121:866-72

21. Cacioppo JT, Petty RE. Social psychological procedures for cognitive response assessment: The thought listing technique. In: Merluzzi T, Glass C, Genest M, eds. Cognitive assessment. New York: Guilford, 1981:309-42.

22. Polkinghorne DE. Narrative knowing and the human sciences. Albany: State University of New York Press, 1988.

23. Glaser BG, Strauss AL. The discovery of grounded theory: strategies for qualitative research. Chicago: Aldine, 1967.

24. Lardner R. Effective shift handover. 2006. http://www.hse.gov.uk//research/996/ ot096003.pdf (accessed 8 Feb 2009).

25. Mullen SS. Adapting strategies from high-reliability organizations to improve patient hand-offs in teaching hospitals. [PhD dissertation]. Athens, Ohio University, 1988

26. Arora V, Johnson JA. Model for building a standardized hand-off protocol. Jt Comm J Qual Patient Saf 2006;32:646-55.

27. Philibert I, Leach DC. Re-framing continuity of care for this century. Qual Saf Health Care 2005:14:394-6.

28. Behara R, Wears RL, Perry SJ, et al. A conceptual framework for studying the safety of transitions in emergency care. Agency for Healthcare Quality, 2005. http://www. ahrq.gov/qual/advances/ (accessed 8 Feb 2009).

29. Hoffrage U, Hertwig R, Gigerenzer G. Hindsight bias: a by-product of knowledge updating? J Exp Psy Learn Mem Cogn 2000;26:566-81.

30. Patterson ES. Communication strategies from high-reliability organizations. Translation is hard work. Ann Surg 2007;245:170-2.

31. Klein G, Feltovich P, Bradshaw JM. Common ground and coordination in joint activity. In: Rouse W, Boff K, eds. Organizational simulation. New York: Wiley, 2005:139-78.

\section{Stay a step ahead with Online First}

We publish all our original articles online before they appear in a print issue. This means that the latest clinical research papers go straight from acceptance to your browser, keeping you at the cutting edge of medicine. We update the site weekly so that it remains as topical as possible. Follow the Online First link on the home page and read the latest research. 